\title{
The feasibility and efficacy of a multidisciplinary intervention with aftercare meetings for fibromyalgia
}

\author{
Mariëlle Kroese • Guy Schulpen • Monique Bessems • \\ Frans Nijhuis • Johan Severens • Robert Landewé
}

Received: 28 October 2008 /Revised: 11 March 2009 /Accepted: 27 March 2009 /Published online: 5 May 2009

(C) The Author(s) 2009. This article is published with open access at Springerlink.com

\begin{abstract}
The objective of this study is to examine the feasibility and long-term results of a 12-week multidisciplinary part-time daycare intervention with five aftercare meetings in fibromyalgia (FM) patients. One hundred and five patients diagnosed with FM started with a multidisciplinary intervention and were assessed for feasibility, functional status (Fibromyalgia Impact Questionnaire [FIQ]), and quality of life (EuroQol-5D [EQ-5D]) until 9 months after completion. The program consisted of sociotherapy, physiotherapy, psychotherapy, and creative arts therapy. Drop-out rate was $4.8 \%$. The attendance rate of 100 patients who completed the 12-week program and five aftercare meetings was high (97.4\%), just like patient and therapist satisfaction (8.2 on a 10 points scale). After the 12-week program, statistically significant improvement was seen in both FIQ and EQ-5D. This improvement was maintained after 9 months of follow-up. On average, moderate improvements were observed. Our 12-week multidisciplinary
\end{abstract}

\author{
M. Kroese $(\bowtie) \cdot$ G. Schulpen $\cdot$ M. Bessems \\ Department of Integrated Care, University Hospital Maastricht, \\ PO Box 5800, 6202 AZ Maastricht, The Netherlands \\ e-mail: marielle.kroese@mumc.nl \\ F. Nijhuis $\cdot$ J. Severens \\ Department of Health Organization, Policy, and Economics, \\ University of Maastricht, \\ Maastricht, The Netherlands \\ J. Severens \\ Department of Clinical Epidemiology \\ and Medical Technology Assessment, University Hospital Maastricht, \\ Maastricht, The Netherlands \\ R. Landewé \\ Department of Internal Medicine, Division of Rheumatology, \\ University Hospital Maastricht, \\ Maastricht, The Netherlands
}

part-time daycare intervention with five aftercare meetings for FM patients is feasible and it is indicated that it can lead to sustained improvement in functional status and quality of life.

Keywords Feasibility · Fibromyalgia ·

Multidisciplinary intervention

\section{Introduction}

Fibromyalgia (FM) is a common chronic pain condition, characterized by generalized pain, stiffness, fatigue, disturbed sleep, psychological distress, and impaired cognitive function $[1,2]$. The cause of and pathologic mechanisms underlying FM are unknown, but FM may lead to disability and reduced quality of life [3].

Increasingly, FM is considered as a combination of physical, psychological, and social disabilities, the biopsychosocial model $[4,5]$. In this model, physical treatment is combined with psychological, behavioral, and/or educational interventions [6]. The studies that have systematically compared monotherapies with treatment combinations that include both physical and psychosocial components have fairly consistently shown that for chronic pain combined treatments result in better outcomes than single therapies [7]. Rossy et al. concluded in their meta-analysis that the optimal intervention for FM would include exercise and cognitive-behavioral therapy [8]. A number of studies have investigated the effect of multimodal or multidisciplinary therapy for FM, but the systematic reviews performed in this area concluded that the evidence is scarce because of few studies, the low quality of the studies, and the varying elements of the therapy [9-11]. Besides, the drop-out rates in the studies are generally high [12-17], suggesting that 
the treatment was not individualized. Another concern is that the majority of the studies did not include long-term follow-up assessments and if they did, that positive outcomes largely disappear in the long-term [11].

Notwithstanding these weaknesses in evidence, multidisciplinary interventions are increasingly applied in the care for patients with FM, even though the costs of the programs are substantial. So methodologically rigorous studies focused on the needs of the patients and the maintenance of the treatment effects in the longer term are needed.

We developed a multidisciplinary intervention which is, especially through the aftercare meetings, aiming at internalization of the learned skills and maintenance of the expected treatment effects. The program tries to link-up with the individual needs of the patients. Before the effectiveness and cost-effectiveness of this multidisciplinary intervention with aftercare meetings could be examined in a randomized controlled trial (RCT), the present study was performed to get an impression about the feasibility of the multidisciplinary intervention in terms of attendance and drop-out rates, as well as about the level of efficacy and sustainability that could be expected.

\section{Materials and methods}

Data collection

Subjects were patients with a diagnosis of FM from the Maastricht University Hospital and recruited between January 2002 and June 2003. After diagnosis, the rheumatologist referred them to a specialized rheumatology nurse. The nurse informed the patients about the multidisciplinary program and asked for motivation to participate and change. Patients had to be between 18 and 65 years of age. Exclusion criteria were illiteracy, pregnancy, involvement in any litigation concerning disability income, specific medical disorders, and diseases making immediate medical treatment necessary or preventing subjects performing physical exercise, and severe psychopathology that would make the patient unable to participate in a group format.

Subjects were assessed nine times: at the start of the program; 1 and 2 months after the start; immediately upon completion of the 12-week program; and 1, 2, 3, 5, and 9 months after completion.

\section{Intervention}

The patients followed a 12-week multidisciplinary intervention, which took place in a part-time daycare setting, so that patients could continue their daily activities such as working, studying, or caring for their children. The program included three mornings a week, two sessions of
$1.5 \mathrm{~h}$ per morning, and took place in groups of eight to nine patients. During 9-months follow-up, the participants took part in five aftercare meetings which took place in decreasing frequency: the first one was scheduled 4 weeks after the 12-week program, the following ones $6,8,10$, and 12 weeks later.

To anticipate the seeking of extra support in the traditional medical care and to link-up with the personal needs, individual treatment options were included in the program (an individual course of maximal $7 \mathrm{~h}$ with one of the different therapists). No physician was involved in the program to prevent the medicalization of FM.

During the 12 weeks, a multidisciplinary team offered a program of sociotherapy, physical therapy, psychotherapy, and creative arts therapy. Sociotherapy (two times a week) was aiming at education (based on transactional analysis [18-20], formulating and evaluating learning goals, training social skills, and making contact with fellow patients. Physiotherapy (two times a week) was focussed at improvement of physical condition (based on graded activity and time-contingent instead of pain-contingent) by fitness exercises and at learning to enjoy exercise. Besides, different forms of relaxation and exercises focusing on alternative patterns of movement were practiced in order to improve awareness and reduce muscle tone during daily activities, and ergonomical advises were given. During the psychotherapy sessions (once a week), general information was presented about FM and the influence of stress on the development and maintenance of the complaints. In these sessions, methods of core qualities [21], rational emotive therapy [22-25], and transactional analysis [18-20] were used. Creative arts therapy (once a week) was used to support the consciousness-raising process.

The intervention was aiming at teaching patients skills necessary to deal with pain and disability, and building confidence so that they could successfully use these skills in their daily lives. The trained skills include social and coping skills, problem solving strategies, behavioral goal setting, adjustment of activities of daily living, and keeping a balance between activity and rest. In the program, self management was explicitly promoted. Patients were encouraged to bear responsibility for their lives and not to victimize themselves. During the treatment, patients were confronted with their pain experience and were focused on their own (problematic) situations. Because of that, they may become more aware of personal difficulties and complaints for which they required counseling. The strength and uniqueness of our intervention is the integration of the general principles in the four therapy methods and the unremitting inter-relationship between these therapy methods.

It is also unique that during the entire program, it was tried to make links with home and job situations in an attempt to stimulate behavioral changes. The five aftercare 
meetings which were aiming at internalizing learned skills were introduced as a relapse prevention. Furthermore, efforts were made to encourage patients to continue to exercise together, e.g. to visit a fitness center at the end of the program. Besides efforts aiming at internalization, explicit attention was paid to motivate the participants to attend the program.

\section{Outcome measures}

Feasibility Feasibility was assessed using the following parameters: drop-out rate (\%), attendance rate (\%), and patient and therapist satisfaction (report marks on a 10 points scale).

Functional status The Fibromyalgia Impact Questionnaire (FIQ), a 10-item self-administered instrument, was used to assess the functional status [26]. The first item focuses primarily on the patient's ability to do large muscle tasks. The next two items represents the number of days in the past week patients felt good and the number of days they missed work. The last seven items - ability to do work, pain, fatigue, morning tiredness, stiffness, anxiety, and depression-are all measured by a visual analog scale (VAS) [26]. All items of the FIQ were standardized on a scale ranging from 0 to 10 with 10 indicating greater impairment [26]. Besides this, a total FIQ score was calculated by adding up the first and the last seven items (range 0-80) [27].

Quality of life The EuroQol-5D (EQ-5D) is a selfadministered, generic instrument that incorporates descriptions and valuations of health states [28]. It consists of five items measuring mobility, self-care, usual activities, pain/ discomfort, and anxiety/depression. Each dimension has three levels of severity, generating a total of 243 theoretically possible health states. The different combinations of responses to the five items are weighted to produce a single index. Following the original work based on a UKpopulation [29], health states were converted to an EQ-5D index score with weights derived from time trade off measurements based on a representative sample of the general population from the Netherlands [30]. The possible states are valued between -0.33 (worst possible state) and 1 (best possible state) [30]. Another part of the EQ is a VAS, on which the patient rates his current health state with endpoints of 100 ('best imaginable health state') at the top and 0 ('worst imaginable health state') at the bottom [28].

\section{Statistical analysis}

Feasibility Percentages and standard deviations were computed for attendance and drop-out rates. Means and standard deviations were calculated regarding the patient and therapist satisfaction.

Efficacy A linear mixed effect model with a random intercept (to integrate the variance due to baseline differences between patients) and a random slope (to integrate the variance due to differences in response over time) was used to investigate the longitudinal response of the multidisciplinary program [31]. Linear mixed models use all available longitudinal data while adjusting for withinpatient correlation. So, patients with incomplete data could be included in this analysis. Since a group effect was anticipated (the intervention took place in groups), we introduced group as a separate level in the linear mixed effect model. Estimated marginal means were calculated for $t_{1}$ (baseline), $t_{4}$ (immediately after completion), and for $t_{9}$ ( 9 months after completion). Because of multiple testing for the estimated marginal means, a significance level of $p<$ 0.01 was applied. In order to assess the magnitude of change, effect sizes (ES) were calculated defined as the change score divided by the baseline SD [32]. For the analysis of the data, SPSS version 11.5 was used [33].

\section{Results}

Of all 105 patients who had started with the intervention, five patients stopped on the advice of the therapists: one patient could not function in a group, two patients experienced problems in their individual life preventing them from further participation, and two patients were diagnosed with psychiatric disorders. These five patients were not included in the subsequent analysis.

Most of the patients who completed the intervention were women, had a secondary education, and had a mean age of approximately 44 years old (Table 1). A large proportion of the patients who started with the program had a recent diagnosis of FM: $50 \%$ started the program within 6 months after diagnosis, $25 \%$ were diagnosed between 6 and 12 months before the start, and only $25 \%$ of the patients were diagnosed more than 12 months before the start of therapy. Fifty-one percent of the patients indicated to have a paid job.

\section{Feasibility}

The attendance rate was very high: $97.8 \%$ for the 12 weeks program and $97.4 \%$ for the 12 -week program including the five aftercare meetings (Table 2). Patients and therapists were generally satisfied with the intervention. They awarded high scores for the entire program, the group atmosphere, and the organization of the program. More 
Table 1 Patient characteristics $(n=100)$

\begin{tabular}{ll}
\hline Characteristic & \\
\hline Sex (\%) & $94(94.0)$ \\
Female & $6(6.0)$ \\
Male & \\
Age (years) & $44.2(9.1)$ \\
Mean (SD) & $19-65$ \\
Range & $($ months $)$ \\
Time between diagnosis and start program & $18.4(28.3)$ \\
Mean (SD) & 6.5 \\
Median & $1-156$ \\
Range & \\
Level of education (\%) & $31(31.0)$ \\
Low & $54(54.0)$ \\
Middle & $14(14.0)$ \\
High & $1(1.0)$ \\
Missing & \\
Paid job (\%) & $51(51.0)$ \\
Yes & $47(47.0)$ \\
No & $2(2.0)$ \\
Missing & \\
\hline
\end{tabular}

than $90 \%$ of the patients considered the program meeting their expectations and $98 \%$ of the patients would recommend the program to someone else (Table 2). No adverse effects were reported.

\section{Efficacy}

A significant longitudinal effect concerning $t_{1}-t_{9}$ was found for all outcomes measures. Table 3 shows the estimated marginal means (EMMs) for the different components of the FIQ at baseline $\left(t_{1}\right)$, immediately after the completion of the 12-week program $\left(t_{4}\right)$, and 9 months after completion $\left(t_{9}\right)$. At the end of the 12-week program $\left(t_{4}\right)$, the EMMs of all items of the FIQ, except the number of missed days at work and stiffness, had significantly improved. One year after start of the program, or 9 months after completion of the program, the improvement obtained at $t_{4}$ had sustained or increased for almost all items. Across all FIQ items, the average effect size was 0.46 at $t_{4}$ and 0.51 at $t_{9}$. Large effect sizes were found for 'number of days felt good' and 'fatigue' ( 0.79 at $\left.t_{9}\right)$. The smallest effect sizes were found for 'number of missed days at work' and 'stiffness' (0.19 at $\left.t_{9}\right)$. With regard to the EQ-5D, both the index and the VAS showed a significant improvement at $t_{4}$ that not only sustained but further increased upon completion of the 12-week program. The effect sizes for the EQ-5D were moderate $\left(0.49\right.$ for the index and 0.69 for the VAS at $\left.t_{9}\right)$.

\section{Discussion}

We concluded that our 12-week multidisciplinary part-time daycare intervention with aftercare meetings was feasible and that the program seems to have a positive effect on functional status and quality of life. Furthermore, there is an indication that the improvement sustains after the completion of the 12-week program.

A low attrition rate and a high compliance suggest that the patients considered the program useful and are an indication that the program meets their expectations, and is not too intensive. As such, attrition rate and compliance reflect feasibility. The drop-out rate during the program was $4.8 \%$, which is substantially lower than the average dropout rate in studies with similar interventions and/or patients. Busch et al. found in their systematic review about exercise and FM attrition rates varying from $12.5 \%$ (range $9 \%$ to $16 \%$ ) in flexibility groups and $14.6 \%$ (SD $11.8 \%$, range $0 \%$ to $40 \%$ ) and $14.8 \%$ (SD $9.6 \%$, range $0 \%$ to $27 \%$ ) in mixed

Table 2 Feasibility $(n=100)$

\begin{tabular}{lll}
\hline & $\begin{array}{l}\text { Patients }(n=100) \\
\text { Mean (SD) }\end{array}$ & $\begin{array}{l}\text { Therapist }(n=5) \\
\text { Mean (SD) }\end{array}$ \\
\hline Attendance (\%) & & \\
12-week program & $97.8 \%(3.3)$ & \\
12-week program+5 post-treatment care meetings & $97.4 \%(3.3)$ & \\
Satisfaction (on a VAS with 1 and 10 as extremes) & & $8.2(0.45)$ \\
Entire program & $8.2(0.88)$ & $6.8(0.45)$ \\
Information before the start of the program & $7.0(1.13)$ & $7.8(0.76)$ \\
Information during the program & $7.8(0.74)$ & $8.1(0.55)$ \\
Accommodation & $7.3(1.37)$ & $8.2(0.45)$ \\
Atmosphere group & $8.4(1.17)$ & $100 \%$ \\
Organization program & $8.3(1.01)$ & $100 \%$ \\
Meeting expectations (yes/no): \% yes & $90.5 \%$ & $0.71)$ \\
Recommend the program to someone else (yes/no): $\%$ yes & $98.0 \%$ & \\
\hline
\end{tabular}


Table 3 Estimated marginal means and effect sizes for baseline, the end of the 12-week program and 9 months after completion with baseline as reference category

\begin{tabular}{|c|c|c|c|c|c|c|c|c|}
\hline & \multicolumn{2}{|c|}{ Baseline } & \multicolumn{3}{|c|}{ At the end of the 12-week program } & \multicolumn{3}{|c|}{9 months after completion of the 12 week program } \\
\hline & Mean & SE & Mean & SE & ES & Mean & SE & ES \\
\hline \multicolumn{9}{|l|}{ FIQ } \\
\hline Physical function & 4.8 & 0.2 & $4.3^{* *}$ & 0.2 & 0.32 & $4.2 *$ & 0.3 & 0.43 \\
\hline Feel good & 7.0 & 0.3 & $5.5^{* *}$ & 0.3 & 0.66 & $5.2 * *$ & 0.5 & 0.79 \\
\hline Work missed & 4.0 & 0.5 & 4.7 & 0.5 & 0.20 & 3.0 & 0.5 & 0.19 \\
\hline Job ability & 7.1 & 0.3 & $6.0 * *$ & 0.3 & 0.44 & $6.1^{*}$ & 0.3 & 0.46 \\
\hline Pain & 6.9 & 0.2 & $6.2^{*}$ & 0.2 & 0.39 & 6.3 & 0.3 & 0.44 \\
\hline Fatigue & 7.9 & 0.2 & $6.9^{* *}$ & 0.2 & 0.62 & $6.9^{*}$ & 0.4 & 0.78 \\
\hline Morning tired & 7.4 & 0.2 & $6.6^{* *}$ & 0.2 & 0.39 & $6.6^{*}$ & 0.3 & 0.54 \\
\hline Stiffness & 6.7 & 0.2 & 6.4 & 0.2 & 0.24 & 6.5 & 0.3 & 0.19 \\
\hline Anxiety & 5.2 & 0.3 & $4.3^{*}$ & 0.3 & 0.33 & 4.1 & 0.5 & 0.36 \\
\hline Depression & 4.4 & 0.3 & $3.6^{* *}$ & 0.3 & 0.30 & $3.5^{* *}$ & 0.3 & 0.29 \\
\hline Total & 50.7 & 1.3 & $43.5^{* *}$ & 1.5 & 0.66 & $43.1^{*}$ & 2.7 & 0.65 \\
\hline \multicolumn{9}{|l|}{ EQ-5D } \\
\hline Index & 0.40 & 0.03 & $0.51 * *$ & 0.03 & 0.40 & $0.55 * *$ & 0.03 & 0.49 \\
\hline VAS & 46.8 & 1.8 & $55.5^{* *}$ & 1.9 & 0.54 & $57.3^{* *}$ & 2.0 & 0.69 \\
\hline
\end{tabular}

The items on the FIQ have been standardized and range from $0-10$. The range of FIQ total is $0-80$. Higher score values indicate worse health status. ${ }^{*} p \leq 0.01 ; * * \leq 0.001$

exercise interventions and multimodal interventions, respectively, to $27 \%$ (SD $18.9 \%$, range $0 \%$ to $67 \%$ ) in aerobic exercise interventions [34]. A systematic review in chronic pain patients yielded a drop-out rate of $14 \%$ for cognitive behavior therapy [35]. These reviews indicate that multimodal interventions has a lower attrition rate than exercise only interventions and that the attrition rate in our program is about the lowest in FM. The patients, who had not completed the multidisciplinary program, were all stopped on the advice of the therapists. Participants who completed the multidisciplinary program attended $97.4 \%$ of the sessions which is nearly complete attendance. This attendance rate outweighed comparable intervention programs importantly [36-38]. Our compliance rate reflects a combination of the positive experiences people had at the sessions, the perceived efficacy of the program throughout the intervention period, the benefit of the group dynamics, and commitment of the subjects to the project and themselves. As a consequence, patient satisfaction was rated as high. These findings together demonstrate the feasibility of the 12-week multidisciplinary part-time daycare intervention with five aftercare meetings for FM patients.

Although the design of this pilot study does not allow a formal evaluation of the efficacy of this intervention, a few remarkable findings should be discussed. First, improvement was measured on all domains of the FIQ and the EQ$5 \mathrm{D}$ suggesting that the effect of the multifaceted approach involves global health rather than specific domains such as pain or fatigue. The generally moderate treatment effects that we have found are comparable with treatment effects in pharmaceutical and non-pharmaceutical trials for FM [8, 39, 40]. For the FIQ version (range 0-80) we used, the average change in total score was reported to be approximately $19 \%$ (9 points) in FM trials [41]. We have found a change of $15 \%$. For the EQ-5D, we found a clinically relevant improvement of $38 \%$ for the index score and $23 \%$ for the VAS. In contrast with other studies in FM patients, the majority of our patients were recently diagnosed. An early intervention in FM patients seems important, because intervening early in the course of a chronic pain condition may help prevent the vicious cycle of long-term physical and psychological suffering. Besides, maladaptive patterns of pain-coping and illness behaviors that might have ingrained after a long-lasting period of FM could make it more difficult to change behavior [11]. However, we could not demonstrate that an early intervention had any influence on the response to our program. Second, and more important, the results of this pilot study strongly suggest that there is sustained improvement over time after completion of the 12-week treatment program, possibly also intensified by the aftercare meetings. As such, the results give an indication that the patients indeed have learned to deal with their disability (coping) and as a consequence experience a better quality of life, which was an important goal of this intervention. This sustained improvement (after completion of the 12-week program) 
encourages us in the idea that the observed advance is worth this moderately intensive treatment.

In the literature, we found only one related study which evaluated the feasibility of an inpatient aftercare week after a rehabilitation program [42]. The scarcity of available evidence makes it difficult to recommend about an optimal number of aftercare meetings and about the optimal time interval. Expectedly, the intervals may become longer over time once the learned principles have been better incorporated.

Of course, the lack of a prognostically comparable control group limits the interpretation of efficacy importantly. Part of the measured effect is undoubtedly attributable to aspecific effects (regression towards the mean). Although most longitudinal studies with FM patients indicate an absence of spontaneous improvement in symptoms or remission in the natural course of FM [4346], aspecific improvement that sustained for at least 9 months cannot entirely be excluded.

Theoretically, it is also possible that the group contact with "fellow patients" rather than the specific content of the program is responsible for the measured improvement. We will further investigate this possibility in the context of a RCT, which has been started based on the results of this feasibility study.

This RCT, which examines the effectiveness and costeffectiveness of the multidisciplinary intervention with aftercare meetings, has an extra long follow-up period of 18 months. Primary outcome measures are social participation (including work), medical consumption, and quality of life.

Although the RCT will provide definitive answers, this study showed that a 12-week multidisciplinary intervention with aftercare meetings for FM is feasible and can lead to sustained improving of functional status and quality of life.

Acknowledgment Thanks to Ilse Klein Goldewijk and Yvonne van Eijk-Hustings, the rheumatology nurses, for selecting the patients for this study; Iris Kalanitsch, Marian van der Pijl, Ludwig Schillings, Mireille de Moor, Bea Rijks, and Lutgart Bastiaens, the treatment team of Huize Blankenberg, who gave the program and cared for the data collecting and Henk Sonneveld who did the feasibility data input.

\section{Disclosures None.}

Open Access This article is distributed under the terms of the Creative Commons Attribution Noncommercial License which permits any noncommercial use, distribution, and reproduction in any medium, provided the original author(s) and source are credited.

\section{References}

1. Wolfe F (1994) When to diagnose fibromyalgia. Rheum Dis Clin North Am 20(2):485-501

2. Wolfe F, Smythe HA, Yunus MB, Bennett RM, Bombardier C, Goldenberg DL et al (1990) The american college of rheumatology
1990 criteria for the classification of fibromyalgia. Report of the multicenter criteria committee. Arthritis Rheum 33(2):160-172

3. Mease P (2005) Fibromyalgia syndrome: review of clinical presentation, pathogenesis, outcome measures, and treatment. J Rheumatol 75:6-21

4. Waddell G (2006) Preventing incapacity in people with musculoskeletal disorders. Br Med Bull 77-78:55-69

5. Ferrari R (2000) The biopsychosocial model - a tool for rheumatologists. Bailliere's best practice and research. Clin Rheumatol 14(4):787-795

6. Allegrante JP (1996) The role of adjunctive therapy in the management of chronic nonmalignant pain. Am J Med 101(1a): $33 \mathrm{~s}-39 \mathrm{~s}$

7. Turk DC (2001) Combining somatic and psychosocial treatment for chronic pain patients: perhaps $1+1$ does $=3$. Clin J Pain 17 (4):281-283

8. Rossy LA, Buckelew SP, Dorr N, Hagglund KJ, Thayer JF, McIntosh MJ et al (1999) A meta-analysis of fibromyalgia treatment interventions. Annals Behav Med 21(2):180-191

9. Karjalainen K, Malmivaara A, van Tulder M, Roine R, Jauhiainen M, Hurri $\mathrm{H}$ et al (2000) Multidisciplinary rehabilitation for fibromyalgia and musculoskeletal pain in working age adults. Cochrane database of systematic reviews Online Update Software (2):Cd001984

10. Sim J, Adams N (2002) Systematic review of randomized controlled trials of nonpharmacological interventions for fibromyalgia. Clin J Pain 18(5):324-336

11. van Koulil S, Effting M, Kraaimaat FW, van Lankveld W, van Helmond T, Cats H et al (2007) Cognitive-behavioural therapies and exercise programmes for patients with fibromyalgia: state of the art and future directions. Ann Rheum Dis 66(5):571-581

12. Astin JA, Berman BM, Bausell B, Lee WL, Hochberg M, Forys KL (2003) The efficacy of mindfulness meditation plus Qigong movement therapy in the treatment of fibromyalgia: a randomized controlled trial. J Rheumatol 30(10):2257-2262

13. Cedraschi C, Desmeules J, Rapiti E, Baumgartner E, Cohen P, Finckh A et al (2004) Fibromyalgia: a randomised, controlled trial of a treatment programme based on self management. Ann Rheum Dis 63(3):290-296

14. King SJ, Wessel J, Bhambhani Y, Sholter D, Maksymowych W (2002) The effects of exercise and education, individually or combined, in women with fibromyalgia. J Rheum 29(12):2620-2627

15. Nicassio PM, Radojevic V, Weisman MH, Schuman C, Kim J, Schoenfeld Smith K et al (1997) A comparison of behavioral and educational interventions for fibromyalgia. J Rheum 24(10):2000 2007

16. Wigers SH, Stiles TC, Vogel PA (1996) Effects of aerobic exercise versus stress management treatment in fibromyalgia: a 4.5 year prospective study. Scand J Rheumatol 25:77-86

17. Zijlstra TR, van de Laar MA, Bernelot Moens HJ, Taal E, Zakraoui L, Rasker JJ (2005) Spa treatment for primary fibromyalgia syndrome: a combination of thalassotherapy, exercise and patient education improves symptoms and quality of life. Rheumatology Oxford, England 44(4):539-546

18. Berne E (1958) Transactional analysis: a new and effective method of group therapy. Am J Psychother 12:735-743

19. Berne E, Steiner CM, Dusay JM (1996) Transactional analysis. In: Groves JE (ed) Essential papers on short term dynamic therapy. Essential papers in psychoanalysis. New York University Press, New York, pp 149-170

20. Cole M (1993) Injunctions and secondary gains in chronic pain patients. Trans Anal J 23(4):191-194

21. Ofman D (2001) Core qualities; a gateway to human resources. Scriptum, Schiedam

22. Ellis A (1969) Rational-emotive therapy. J Contemp Psychother 1(2):82-90 
23. Ellis A (2002) Overcoming resistance: a rational emotive behavior therapy integrated approach, 2nd edn. Springer, New York

24. Rothschild BH (1993) RET and chronic pain. In: Dryden W, Hill LK (eds) Innovations in rational-emotive therapy. Sage, Thousand Oaks, pp 91-115

25. Morris GB (1998) Changing people from tender-minded to toughminded: a PATHWAY for dealing with chronic pain. In: Klarreich S (ed) Handbook of organizational health psychology: programs to make the workplace healthier. Psychosocial, Madison, pp 139-155

26. Burckhardt CS, Clark SR, Bennett RM (1991) The fibromyalgia impact questionnaire: development and validation. J Rheumatol 18(5):728-733

27. Burckhardt CS, Mannerkorpi K, Hedenberg L, Bjelle A (1994) A randomized, controlled clinical trial of education and physical training for women with fibromyalgia. J Rheumatol 21(4):714-720

28. The EuroQol Group (1990) EuroQol - a new facility for the measurement of health-related quality of life. Health Policy 16 (3):199-208

29. Dolan P (1997) Modeling valuations for EuroQol health states. Med Care 35(11):1095-1108

30. Lamers LM, Stalmeier PF, McDonnell J, Krabbe PF, van Busschbach JJ (2005) Kwaliteit van leven meten in economische evaluaties: het Nederlands EQ-5D-tarief [Measuring the quality of life in economic evaluations: the Dutch EQ-5D tariff]. Nederlands tijdschrift voor geneeskunde 149(28):1574-1578

31. Landau S, Everitt BS (2004) Analysis of repeated measures II: linear mixed effect models; computer delivery of cognitive behavioral therapy. In: A handbook of statistical analyses using SPSS. Boca Raton: Chapman \& Hall/CRC Press LLC pp 189-219

32. Cohen J (1988) Statistical power analysis for the behavioral sciences, 2nd edn. Lawrence Erlbaum Associates, Hillsdale

33. SPSS. SPSS 11.5 for Windows Update. In. Chigago, IL 60606; 2002.

34. Busch AJ, Schachter CL, Overend TJ, Peloso PM, Barber KA (2008) Exercise for fibromyalgia: a systematic review. J Rheumatol 35(6):1130-1144

35. Morley S, Eccleston C, Williams A (1999) Systematic review and meta-analysis of randomized controlled trials of cognitive behav- iour therapy and behaviour therapy for chronic pain in adults, excluding headache. Pain 80(1-2):1-13

36. Gowans SE, deHueck A, Voss S, Richardson M (1999) A randomized, controlled trial of exercise and education for individuals with fibromyalgia. Arthritis Care Res 12(2):120-128 The official journal of the Arthritis Health Professions Association

37. van Santen M, Bolwijn P, Verstappen F, Bakker C, Hidding A, Houben $\mathrm{H}$ et al (2002) A randomized clinical trial comparing fitness and biofeedback training versus basic treatment in patients with fibromyalgia. J Rheumatol 29(3):575-581

38. Haugli L, Steen E, Laerum E, Finset A, Nygaard R (2000) Agency orientation and chronic musculoskeletal pain: effects of a group learning program based on the personal construct theory. Clin J Pain 16(4):281-289

39. Carville SF, Choy EH (2008) Systematic review of discriminating power of outcome measures used in clinical trials of fibromyalgia. J Rheumatol 35(11):2094-2105

40. Dunkl PR, Taylor AG, McConnell GG, Alfano AP, Conaway MR (2000) Responsiveness of fibromyalgia clinical trial outcome measures. J Rheumatol 27(11):2683-2691

41. Burckhardt CS (2002) Nonpharmacologic management strategies in fibromyalgia. Rheum Dis Clin North Am 28(2):291-304

42. Ehlebracht Konig I, Bonisch A (2004) Stationare Nachsorge bei rheumatischen Erkrankungen -Konzept, Erprobung und Akzeptanz [Inpatient aftercare in rheumatic diseases-concept, trial, and acceptance]. Rehabilitation (Stuttg) 43(6):358-367

43. Nöller V, Sprott H (2003) Prospective epidemiological observations on the course of the disease in fibromyalgia patients. BMC Journal of Negative Results 2(1):4

44. Ledingham J, Doherty S, Doherty M (1993) Primary fibromyalgia syndrome - an outcome study. Br J Rheumatol 32(2):139-142

45. Baumgartner E, Finckh A, Cedraschi C, Vischer TL (2002) A six year prospective study of a cohort of patients with fibromyalgia. Ann Rheum Dis 61(7):644-645

46. Wolfe F, Anderson J, Harkness D, Bennett RM, Caro XJ, Goldenberg DL et al (1997) A prospective, longitudinal, multicenter study of service utilization and costs in fibromyalgia. Arthritis Rheum 40(9):1560-1570 